\title{
The Utilization of Benchmarking in the Jordanian Banking Sector
}

\author{
Dr. Hussien Al-Tarawneh \\ Business Faculty, The World Islamic Sciences \& Education University \\ Amman, Jordan \\ E-mail: Hat3ms@yahoo.com,dr.hussient@gmail.com
}

Received: April 9, 2014

Accepted: June 3, 2014

Published: July 1, 2014

doi:10.5296/jmr.v6i3.5299

URL: http://dx.doi.org/10.5296/jmr.v6i3.5299

\begin{abstract}
This paper aims to investigate and highlight the impact of utilizing benchmarking in the Jordanian banking sector. The literature and previous studies examined the benchmarking in different environments and circumstances. A questionnaire survey was used to obtain information about Benchmarking practices and overall business performance from 12 different commercial banks in Jordan. That data was used to examine the effects of Benchmarking practices on the development and performance of these banks. Benchmarking is an effective managerial tool to help managers make sound and fast organizational plans, it leads to customer satisfaction, and it significantly related to the quality of services and performance.
\end{abstract}

Keywords: Benchmarking- Banking sector- Benchmarking stages 


\section{Introduction}

Benchmarking at first glance may be mistaken for a copycat form of developing strategic plans and for making improvements within an organization. This is not true. Benchmarking is a process that allows organizations to improve upon existing ideas. In order to reduce myths and misconceptions about benchmarking it is important to know exactly what benchmarking is, the different types of benchmarking, the key benefits of benchmarking.

Benchmarking is the process whereby an organization internments specific data related to its costs and performance - i.e., the baseline, or current state of the organization under studyand then evaluates this cost and performance data against those from some other body (which constitutes the actual benchmarking).

The knowledge that is available for comparing operations and processes are vast (Boxwell, 1994). “An organization's ability to evaluate its practices against specific business strategies and objectives is critical to leveraging its knowledge capital” (Harper, 1996). Information is there for organizations and it should be evaluated, used, and shared. This is one of the primary goals of benchmarking. It is the process of using all of the knowledge and experience of others to develop new and fresh ideas. This is basic teamwork, which is the way progressive organizations are migrating. Many organizations are realizing how much more can be achieved if there is more collaboration between leaders in an industry.

\section{Literature Review}

Benchmark is a measurement of the quality of an organization's policies, products, programs, strategies, etc., and their comparison with standard measurements, or similar measurements of its peers.

The objectives of benchmarking are (1) to determine what and where improvements are called for, (2) to analyze how other organizations achieve their high performance levels, and (3) to use this information to improve performance. Others define benchmarking that it is simply the comparison of one organization's practices and performance against those of others. It seeks to identify standards, or "best practices," to apply in measuring and improving performance. One more definition for benchmarking describes it as a standard against which the performance of a security, mutual fund or investment manager can be measured. Generally, broad market and market-segment stock and bond indexes are used for this purpose.

A benchmark is a point of reference by which something can be measured. In surveying, a "bench mark" (two words) is a post or other permanent mark established at a known elevation that is used as the basis for measuring the elevation of other topographical points. Different studies were conducted to assess the impact of utilizing benchmarking in different sectors, for example Dragolea \&Cotîrlea,(2009) dealt with a popular method for developing requirements and setting goals - benchmarking. Their paper contained general aspects about this powerful performance improvement tool, including types of benchmarking, steps to follow in Benchmarking analysis, its goals, the benefits in using it and some dangers caused by using it, also; the whole paperwork can be considered as being a plea for continuous, 
ongoing, unending improvement in management context and sustains the idea that benchmarking enables decision-makers to understand exactly how much improvement they will need to accomplish in order to achieve superior performance. The case study examined the benchmarking initiatives taken by Xerox, one of the world's leading copier companies, as a part of its 'Leadership through Quality' program; the case discusses the benchmarking concept and its implementation in various processes at Xerox and it also explores the positive impact of benchmarking practices on this company.

Sajjad \& Amjad, (2012) presented the importance of benchmarking in TQM and organizational performance. To determine the various benefits an organization can derive from the application of total quality management practices, or the relationship between total quality management and quality outcomes/benefits in services sector of telecom industry of Pakistan. The study was based on primary and secondary data. Eight most important constructs were found through literature review for conceptual framework in this study. Primary data was collected through questionnaires. The same questionnaire was used in comparison of TQM practices in different countries such as India, USA, Mexico, China and Norway. The theoretical framework adopted is by Raghunathan et al. (1999). Findings revealed that TQM practices and implementation have positive effects on quality benefits or outcome (productivity, profitability, competitive position, reduce customer complaints, cost reduction, reduce rework level, reduces scrap level, stay in business) in services sector of telecom industry of Pakistan. Benchmarking also plays a significant role in the development of organizations. In addition to the research data, findings from different field studies and other research works have further supported conclusion drawn from this research, that TQM practices have positive effect on organizational development. The findings based on this empirical research would be useful to both decision makers and researchers.

Yasin, (2002), summarized in "The theory and practice of benchmarking: then and now", that despite the increasing scope of benchmarking activities and the number of organizations utilizing benchmarking, the impact of benchmarking remains to a large extent without a unifying theory to guide its advancement. Also, a call is given to develop innovative methodologies to guide benchmarking practices in e-commence and supply .chain management.

Andersen in his paper "Industrial Benchmarking for Competitive Advantage" dealt with several different aspects of the concept of benchmarking in order to give the audience a basic understanding of what benchmarking is, how it is done, and what it can give in terms of improvement results. The main issues covered are definitions of benchmarking and the core concept of comparison for the sake of improvement, explanations of the different types of benchmarking that exist and what implications these have, both in terms of improvement potential, difficulties, and suitability. Furthermore, ethical and legal aspects linked to benchmarking and the benchmarking wheel, a benchmarking process model explaining the phases and steps of the benchmarking study. A relatively large portion of the paper was devoted to explaining how to carry out a benchmarking study and various pitfalls that might be encountered. The remainder of the paper discussed the improvement results that companies that have used benchmarking actually have achieved. 


\section{Macrothink}

Journal of Management Research

ISSN 1941-899X

2014, Vol. 6, No. 3

Raymond, (2008) in her paper "Benchmarking in public procurement" investigated the technique of benchmarking to improve the quality of the public procurement process and discussed the importance of benchmarking to overcome perceived weaknesses with these processes. This is followed by a case study of Sri-Lanka, exploring the difficulties faced by public sector employees in separating the daily business of government from the political influences of its elected leaders. The literature review was used to examine the key principles of government procurement and how they could be benchmarked. This formed the theoretical base for the discussion. The case study of Sri-Lanka has been used very effectively to discuss the experiences of developing countries. The findings revealed that reform solutions within government procurement systems must include measures that address issues of accountability, transparency, value for money, a professional work force and ethics. The major limitation of this study is that it relies solely only on the experience of Sri-Lanka. Perhaps including the experiences of other developing countries such as India, Bangladesh and Indonesia could increase the transference of findings of Sri-Lanka to these countries as well.

\section{Benchmarking Implementation Phases}

There are five phases for implementation of benchmarking:

\subsection{PLANNING}

During this phase the organization determines which process to benchmark and against what type of organization.

\subsection{ANALYSIS}

Following data acquisition, an analysis is performed for the performance gap between the source organization and the recipient organization. An indication of best practices then evidence.

\subsection{INTEGRATION}

It involves the preparation of the recipient for implementation of actions.

\subsection{ACTION}

This is the phase where the actions are implemented within the recipient organization.

\subsection{MATURITY}

This involves continuous monitoring of the process and enables continuous learning and provides input for continuous improvement within the recipient organization.

\section{Types of Benchmarking:}

There are three primary types of benchmarking that are in use today. These are process benchmarking, performance benchmarking, and strategic benchmarking (Bogan, 1994).

\subsection{Process benchmarking}

Process benchmarking focuses on the day-to-day operations of the organization. It is the task 
of improving the way processes performed every day. Some examples of work processes that could utilize process benchmarking are the customer complaint process, the billing process, the order fulfillment process, and the recruitment process (Bogan, 1994). All of these processes are in the lower levels of the organization. By making improvements at this level, performance improvements are quickly realized. This type of benchmarking results in quick improvements to the organization.

\subsection{Performance benchmarking}

Performance benchmarking focuses on assessing competitive positions through comparing the products and services of other competitors. When dealing with performance benchmarking, organizations want to look at where their product or services are in relation to competitors on the basis of things such as reliability, quality, speed, and other product or service characteristics.

\subsection{Strategic benchmarking}

Strategic benchmarking deals with top management. It deals with long term results.

Strategic benchmarking focuses on how companies compete. This form of benchmarking looks at what strategies the organizations are using to make them successful. This is the type of benchmarking technique that most Japanese firms use (Bogan, 1994). This is due to the fact that the Japanese focus on long term results.

Other types of benchmarking are competitive benchmarking, cooperative benchmarking collaborative and internal (Boxwell, 1994). Competitive benchmarking is the most difficult type of benchmarking to practice. For obvious reasons, organizations are not interested in helping a competitor by sharing information. This form of benchmarking is measuring the performance, products, and services of an organization against its direct or indirect competitors in its own industry. Competitive benchmarking starts as basic reverse engineering and then expands into benchmarking. Reverse engineering is a competitive tool used in benchmarking. It looks at all aspects of the competition's strategy. This does not just include the disassembly and examination of the product but it analyzes the entire customers' path of the organization's competitor. This is a difficult thing to do because this information is not easily obtained. Therefore, it requires extensive research. It is also important to remember when using competitive benchmarking that the goal is to focus on your direct competitors and not the industry as a whole.

"Cooperative and collaborative benchmarking are the most widely used types of benchmarking because they are relatively easy to practice” (Boxwell, 1994). These forms of benchmarking are a more accommodating way of getting information. In cooperative benchmarking, organizations invite best in class organizations to meet with their benchmarking team to share knowledge. This is usually done without much controversy because these organizations are not direct competitors. During this process information flows one way. From the "best in class" organization to the benchmarking team organizations. Collaborative benchmarking does the opposite, information flows many ways. With collaborative benchmarking, information is shared between groups of firms. It is a 


\section{Macrothink Institute ${ }^{\mathrm{TM}}$}

brainstorming session among organizations. It is important to realize that not all collaborative efforts are considered benchmarking. It is sometimes called "data sharing." Data sharing results do not focus on the process but only the end result, while benchmarking focuses on the processes of the organizations (Boxwell, 1994).

\section{Key Benefits of Benchmarking}

\subsection{Actionable information to help companies grow}

Organizations that regularly benchmark their operations use these insights to map their strengths and weaknesses. With continuous monitoring and data in hand, organizations can react faster and make the appropriate adjustments.

\subsection{Quantitative information drives strategic decisions and initiatives}

Insight into the business processes or systems allows organizations to focus on the right levers for growth. Knowing what waste to cut or where investments need to be made based on data - driven evidence gives executives confidence in their decisions.

\subsection{Reduced uncertainty}

Benchmarking provides quantitative evidence that helps companies measure any change in performance. A significant benefit of benchmarking is the insight into critical business processes it provides thereby enabling managers to proactively craft solutions to address issues.

\subsection{Tactical Action Plan}

Misallocation of resources is often a result of an inefficient or ineffective process. Comparing the process, staff, and systems involved in relation to a peer group allows managers to address laggard processes with less effort and greater knowledge.

\subsection{Enhanced understanding of cost structure relative to others}

Comparing relative business costs to top organizations and peers can drive the initiative to improve processes, systems, or staff functions to gain a competitive advantage.

\section{Objectives}

The main purpose of this research is:

1) To assess the effects of Benchmarking on overall performance in banking sector in Jordan

2) To assess the significance of Benchmarking for organizational development.

\section{Hypotheses}

In the light of above objectives the following hypotheses are:

H1: Benchmarking helps to enhance performance of an organization in banking sector in Jordan.

$\mathrm{H} 2$ : The extent of use of benchmarking is significantly related to the quality of services and 
performance.

H3: Benchmarking also leads to customer satisfaction.

\section{Research Methodology}

In this study, the questionnaire survey was used to obtain information about Benchmarking practices and overall business performance from 12 different commercial banks in Jordan. That data was used to examine the effects of Benchmarking practices on the development and performance of these banks. The type of samples and the number of banks were determined on the basis of meeting the information and requirements for the research. The survey instrument adopted in this research was a pre-tested questionnaire with some modifications that were suitable for this study. The questionnaire consisted of 12 related statements in five categories. These categories correspond to Benchmarking stages.

The items were written in the form of statements to which the respondents responded using a five-point Likerts type scale (ranging from very high to very low). The research questionnaires were sent to human resource management department in the sampled banks.

\section{Data Analysis and Results}

Two hundred questionnaires along with a covering letter were distributed among the selected sample. It explained the purpose of the study and the importance of the participation of the employees in responding to the questionnaires.

There were 185 responses from the 200 questionnaires. It is a response rate of 93\%, which is at a satisfactory level. However 180 questionnaires were selected for this analysis. It shows that $80 \%$ of the respondents were male employees while the rest were female employees. The majority of the employees appear to be within the age group of 36-50(60\%).The highest number of respondents has been employees with BA degree qualification (48\%) while rest $30 \%$ and $22 \%$ of employees were Master degree qualifications. The respondents have been from majority group having job experience of 6-10 years. There were $85 \%$ of married and $15 \%$ single employees in the sample.

Analyzing the implementation stages of Benchmarking among Jordanian banks revealed that 13.3\% of Jordanian commercial banks had not considered using the benchmarking in their work. One interesting finding indicates that $17.3 \%$ of the responding banks were implementing benchmarking approach and $12.5 \%$ considering it. Only $1.8 \%$ of the responding banks that had first implemented the Benchmarking approach had then subsequently abandoned it.

These results are a positive indicator about the trend for the future diffusion of Benchmarking approach among Jordanian banks. The results of the study indicated that the use of Benchmarking is spread across commercial banks in Jordan. The findings also indicate that $38.3 \%$ of the responding banks who were implementing benchmarking approach expressed that Benchmarking implementation leads to improve customer satisfaction by a percent of $87 \%$, since Benchmarking affects their quality of work and the quality of the provided services these factors impacted customers' satisfaction. 


\section{Conclusion.}

Benchmarking enables decision-makers to understand exactly how much improvement they will need to accomplish in order to achieve superior performance. Frequent and regular benchmarking helps us to create specific and measurable short-term plans that are based on current reality rather than historical performance, and which can support step-by-step improvements in performance over time. The objective is to overtake the top performers, turning a performance deficit into performance leadership.

It is necessary to evaluate this study in the context of its limitation.

First, data used to test the theoretical models came from 12 commercial banks. So generalization is limited.

Second, the measure of top management commitment perceived is relatively weak, because it asked respondents for their general perception of top management commitment in their respective bank.

Third, all primary data were obtained from respondents through questionnaire. Response was on their perceptions, thus research findings might have been biased. However these limitations in the study leave future ground for explorations and research on the subject.

Investing in Benchmarking stages and implementation often requires a long term effort and a great deal of energy, money, patience and management attention.

\section{References}

Andersen, Bjørn. Industrial Benchmarking for Competitive Advantage, Norwegian University of Science and Technology, N-7034 Trondheim, Norway.

Bogan, Christopher. (1994). Benchmarking Best Practices, McGraw Hill.

Boxwell, Robert. (1994). Benchmarking for a Competitive Advantage, McGraw Hill.

Dragolea, Larisa and Cotîrlea, Denisa (2009), BENCHMARKING - A VALID STRATEGY FOR THE LONG TERM? Annales Universitatis Apulensis Series Oeconomica, 11(2).

Graham, Anne. (1997). Association Publications: Benchmarking Common Problems. The Magazine for Magazine Management, 25.

Harper, Kim. (1996). Benchmarking: International Clearinghouse Plays Matchmaker for Companies That Want to Improve. Arkansas Business, 9.

Parker, Sally. (1996). Measuring up: Size is No Obstacle to Benchmarking for Competitive Advantage. Rochester Business Journal, 8.

Sajjad, Faiza, \& Dr.Shehla Amjad. (2012). Role of Benchmarking in Total Quality Management: Case of Telecom Services Sector of Pakistan. Business Management Dynamics, 1(8).

Stevenson, William. (1996). Productions/Operations Management. Irwin Publishing 


\section{Macrothink}

Journal of Management Research ISSN 1941-899X 2014, Vol. 6, No. 3

Company, 5th Edition.

Thompson and Strickland. (1996). Strategic Management - Concepts and Cases. Irwin Publishing Company, 9th Edition.

Raymond, Jeanette (2008). Benchmarking in public procurement, Department of Management, Monash University, Caulfield East. Australia Benchmarking: An International Journal, 15(6).

Yasin, M.M. (2002). The theory and practice of benchmarking: then and now. Benchmarking: An International Journal, 9(3), 217-43. http://dx.doi.org/10.1108/14635770210428992

http://www.businessdictionary.com/definition/benchmarking.html\#ixzz2wCZoyQKH http://www.mad.state.mn.us/benchmarking

http://www.investopedia.com/terms/b/benchmark.asp 